\title{
Early Crohn disease: a proposed definition for use in disease-modification trials
}

\author{
Laurent Peyrin-Biroulet, ${ }^{1}$ Edward V Loftus $\mathrm{Jr},{ }^{1}$ \\ Jean-Frederic Colombel, ${ }^{2}$ William J Sandborn ${ }^{1}$
}

\section{INTRODUCTION}

Crohn disease is a chronic condition characterised by intestinal inflammation and progressive bowel damage associated with impaired functioning.

In rheumatoid arthritis, which shares some common aetiological pathways and treatments with Crohn disease, treatment goals no longer include symptom control alone, but also alteration of the biological processes underlying synovial inflammation and progressive structural destruction, thereby preventing structural joint damage and functional decline. ${ }^{1}$ Analogous disease-modifying treatment goals for Crohn disease are currently being conceptualised and may include prevention of structural bowel damage (stricture, fistula, abscess) and impaired gastrointestinal physiology (ie, maintaining normal gastrointestinal physiology). ${ }^{23}$

In order to achieve disease modification, an effective intervention must occur at the right time, that is, before the development of bowel damage and impaired functioning. While it has been said in this context 'the earlier, the better', there is no formal definition of early Crohn disease. ${ }^{4}$ This article will review the rationale for defining early Crohn disease and the rationale for specifically targeting early Crohn disease from both immunopathological and clinical points of view, using rheumatoid arthritis (another chronic, progressive, destructive disease), as an example. We will then propose a definition of early Crohn disease and briefly discuss its potential application in future clinical trials.

\section{RATIONALE FOR DEFINING EARLY CROHN DISEASE (SEE BOX 1)}

Studies from referral centres have demonstrated that the clinical features of

${ }^{1}$ Inflammatory Bowel Disease Clinic, Division of Gastroenterology and Hepatology, Mayo Clinic, Rochester, Minnesota, USA ${ }^{2}$ Hopital Claude Huriez, Chu Lille, Lille, France

Correspondence to Dr William J Sandborn, Mayo Clinic, 200 First Street SW, Rochester, MN 55905, USA sandborn.william@mayo.edu
Crohn disease change over time with a decreasing frequency of inflammatory (non-stricturing non-penetrating) disease behaviour and an increasing frequency of stricturing and/or penetrating disease behaviour (disease progression). ${ }^{5} 6 \mathrm{Popu}$ lation-based studies have demonstrated that more than $50 \%$ of adult patients with Crohn disease develop stricturing or penetrating intestinal complications within 20 years of diagnosis ${ }^{7}$ and similarly these complications occur in more than $50 \%$ of children after a median follow-up of 84 months. ${ }^{8}$ The development of these complications is associated with a need for surgical resection. Recent populationbased studies reported that the cumulative risk for first intestinal resection in adults with Crohn disease was $64 \%$ at years 30 from diagnosis ${ }^{9}$ and in children $34 \%$ at 5 years from diagnosis. ${ }^{8}$ These data suggest that Crohn disease, similar to rheumatoid arthritis, ${ }^{10}$ is a chronic progressive destructive disease and that effective intervention before the onset of bowel damage (stricture, fistula, abscess) may be required to optimise patient outcomes.

The concepts of 'a therapeutic window of opportunity' for early intervention in rheumatoid arthritis and in Crohn disease, aimed at preventing the development of disease complications such as joint or bowel damage, are shown in figures $1,2{ }^{11}$ The identification of patients with early Crohn disease in clinical practice and for enrolment in clinical trials remains a challenge, as no formal definition exists. In clinical practice, early Crohn disease is usually considered as a newly diagnosed case. This definition may be inadequate to alter the clinical course of Crohn disease, since approximately $20 \%$ of adult patients already have evidence of a stricturing or penetrating intestinal complication at diagnosis or within 90 days of diagnosis, and disease complications are present in $29 \%$ of children at diagnosis. ${ }^{8}$

Current concepts of Crohn disease pathogenesis suggest a complex interplay between the host susceptibility genes, ${ }^{12}$ the host intestinal microbiological flora and the environment, resulting in an increased immunological response towards microbiological and self antigens, ${ }^{13}$ followed by the development of subclinical intestinal inflammation that can be considered as the earliest form of Crohn disease ${ }^{14}$ (figure 2). In one serum bank study, the presence of anti-Saccharomyces cerevisiae antibody (ASCA) in asymptomatic Israeli military recruits was associated with a subsequent diagnosis of Crohn disease after a median delay of 38 months. ${ }^{15}$ Increased immune reactivity to the intestinal microbiological flora has also been associated with an increased risk of intestinal complications in patients with Crohn disease. ${ }^{16}$

Overall, the preclinical stages of Crohn disease remain unexplored, and the question 'when does Crohn disease start? remains unanswered. Currently, it is not possible to identify individuals at risk of developing Crohn disease, and current molecular tools, such as genetic markers (nucleotide-binding oligomerisation domain containing (NOD2), interleukin (IL)-23 receptor, etc), do not allow the identification of subclinical intestinal inflammation with accuracy. Thus, at present, the only way to define early Crohn disease is to use clinical, biological, endoscopic and radiological criteria (figure 2).

\section{RATIONALE FOR EARLY INTERVENTION IN CROHN DISEASE: LESSONS FROM RHEUMATOID ARTHRITIS (SEE BOX 2) Immunopathological evidence}

Rheumatoid arthritis is a systemic autoimmune disorder primarily affecting the synovium of peripheral joints. ${ }^{17}$ Patients with early rheumatoid arthritis have significantly elevated synovial concentrations of IL-2, IL-4, IL-13 and IL-17 as compared with those with established rheumatoid arthritis. ${ }^{18}$ Later in the disease course of rheumatoid arthritis, increased production of interferon-gamma (IFN- $\gamma$ ) in synovial fluid has been reported. ${ }^{19-21}$ These data indicate a transient $\mathrm{T}$-helper 2 (Th2) disease phenotype in the early phase of rheumatoid arthritis, with a shift towards a Th1 disease phenotype in the late phase of disease.

Immunopathological studies in both animals and humans have also demonstrated that cytokine profiles change during the clinical course of Crohn disease. ${ }^{22-24}$

In experimental murine models of colitis and ileitis, early disease is characterised by Th1 immune responses with upregulation of IL-12 and IFN- $\gamma$, whereas a Th2 phenotype (IL-4 and IL-13) is observed when disease enters the chronic phase. ${ }^{2526}$ 


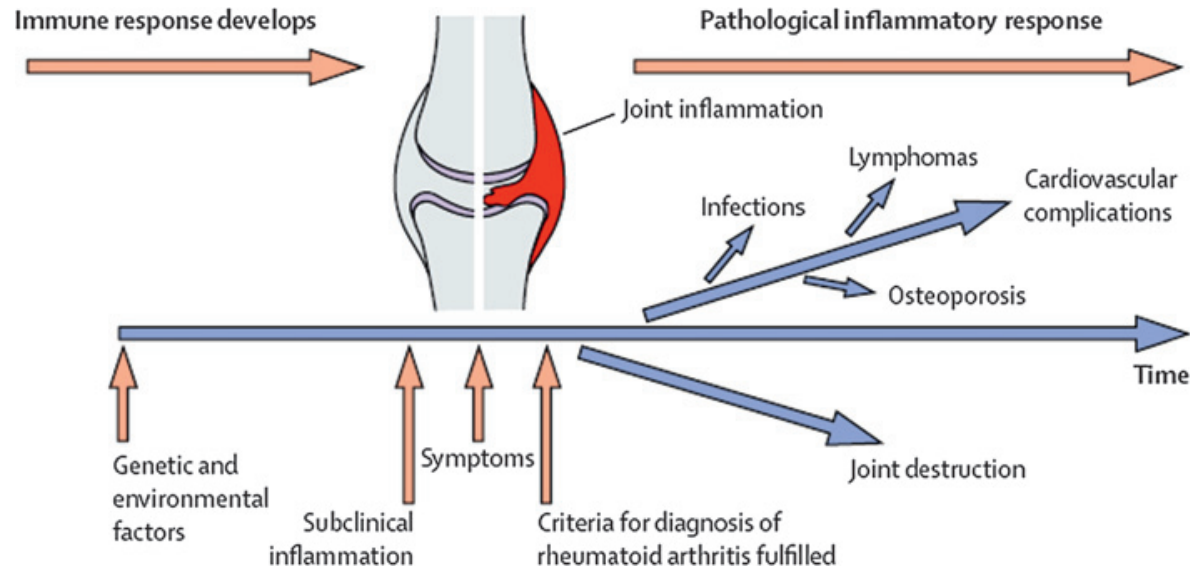

Figure 1 Longitudinal course of rheumatoid arthritis (reprinted with permission from Klareskog et $\left.a l^{11}\right)$.

Whether data from animal models of spontaneous colitis or ileitis could be extrapolated to human Crohn disease has only recently been investigated. Kugathasan et al demonstrated that mucosal T cells derived from colonoscopic biopsies from children with early Crohn disease that were conditioned with IL-12 mounted a Th1 response characterised by elevated concentrations of IFN- $\gamma$, a phenotype that was not observed in mucosal T cells from patients with late disease. ${ }^{24}$ In addition, the colonic mRNA concentrations of IL-12 and IL-12R $\beta 2$ chain were higher in early than late Crohn disease. ${ }^{24}$ In another human study, early endoscopic recurrence of Crohn disease 3 months after ileal resection was associated with a significant increase in IL-4 mRNA concentration and a concomitant decrease in IFN- $\gamma$ mRNA concentration. ${ }^{23}$ In contrast, a significant increase in IFN- $\gamma$ concentration was observed in chronic ileal lesions, together with a marked decrease in IL-4 concentration. ${ }^{23}$

Disease-specific changes also occur in the expression of adhesion molecules and their ligands, ${ }^{27}$ such as the chemokine receptor 9 (CCR9), a highly specific receptor expressed by $\mathrm{T}$ cells migrating selectively to the digestive tract. ${ }^{28}$

The results from these immunopathological studies suggest some potential targets for therapeutic intervention in patients with early Crohn disease, including tumour necrosis factor-alpha (TNF- $\alpha$ ) inhibition with infliximab, adalimumab or certolizumab pegol, and chemokine receptor CCR9 inhibition with CCX282-B. ${ }^{14}$

\section{Evidence from clinical trials}

The first randomised controlled trials in patients with early rheumatoid arthritis were conducted more than 30 years ago. ${ }^{29}{ }^{30}$ Clinical response, progression of disability and erosive damage are now all routinely assessed in early rheumatoid arthritis trials. ${ }^{30}$ Results from recent large trials have demonstrated that combination therapy with TNF- $\alpha$ antagonists and methotrexate prevents disability and radiographic damage in early rheumatoid arthritis. ${ }^{31-35}$ The BeSt (Dutch acronym for Behandel-Strategieën, 'treatment strategies') study enrolled 508 patients with early rheumatoid arthritis and compared four different treatment strategies $^{36}$ : (1) sequential monotherapy; (2) step-up combination therapy; (3) initial combination therapy with prednisone and methotrexate; and (4) initial combination therapy with infliximab and methotrexate. After 4 years of treatment, joint damage progression remained significantly lower after initial combination therapy compared with initial monotherapy. ${ }^{37}$

Safety is an important concern when treating patients with disease-modifying drugs. A potential caveat regarding early use of highly effective combination therapy treatment strategies is the possibility of overtreatment, as some patients will have a mild disease course. All the studies in rheumatoid arthritis showed a tendency for more adverse events with combination therapy independently from disease duration, but the differences between studies are small. $^{30}$ Interestingly, a pooled analysis of clinical trials with TNF antagonists in patients with early rheumatoid arthritis suggested that many adverse effects occur at a lower frequency among patients with early disease. $^{38}$ Patients with early rheumatoid arthritis in general are younger, use concomitant medications less frequently and have less comorbidity than individuals with longstanding rheumatoid arthritis. Whether early intervention with highly effective therapy that is disease-modifying may reduce the risk of adverse events is unknown.

Few studies have been performed in patients with early Crohn disease. Two trials have evaluated the use of early surgical intervention. ${ }^{39} 40$ This idea has limited appeal because it permanently alters the gastrointestinal physiology and function. Both observational and placebo-controlled trials have suggested that azathioprine and 6-mercaptopurine may be more effective when administered to children and adolescents early in the course of their disease. ${ }^{841}$ A small controlled trial demonstrated that 6 mercaptopurine significantly reduced the need for prednisone and was more effective than placebo for maintenance of clinical remission. ${ }^{41}$ In a population-based study from northern France, the use of immunosuppressive therapy in paediatric patients was associated with a decreased risk for surgery. ${ }^{8}$ Moreover, azathioprine was introduced earlier in the course of disease in patients not undergoing surgery than in patients requiring surgery. ${ }^{8}$ In adults, experience from a referral centre suggested that despite increasing use of azathioprine in Crohn disease over time, it did appear not to change surgical rates. ${ }^{42}$ However, these results should be interpreted with caution because less than $10 \%$ of patients followed during this period received azathioprine before surgery, the study was not designed to investigate the impact of azathioprine on surgery rates, and many of the patients likely received azathioprine later in the disease course. $^{42}$

Subgroup analyses from placebocontrolled trials with TNF antagonists have also suggested that patients with early Crohn disease may experience greater efficacy than patients with established disease. ${ }^{43-45}$ One small randomised trial suggested that combination therapy with azathioprine and anti-TNF therapy may be more effective in patients with early Crohn disease. However, no definite conclusions can be drawn from this study, as efficacy results at 2 years were negative, and the authors used an empirical definition of early Crohn disease. ${ }^{46}$

Collectively, these observations suggest that the development of a formal definition of early Crohn disease is needed to facilitate the development of new therapeutic strategies.

\section{PROPOSAL FOR A DEFINITION OF EARLY CROHN DISEASE FOR USE IN CLINICAL TRIALS (SEE BOX 3)}

\section{Example of rheumatoid arthritis}

Early rheumatoid arthritis is defined by the American College of Rheumatology 


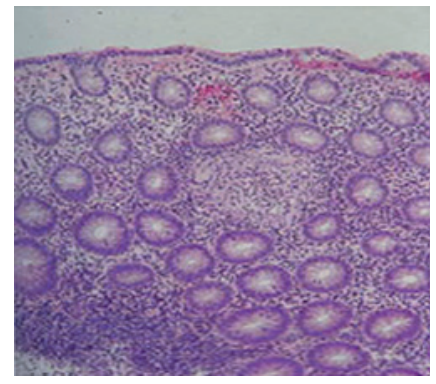

Preclinical phase:

Subclinical inflammation

(Immune response and histologic lesions)

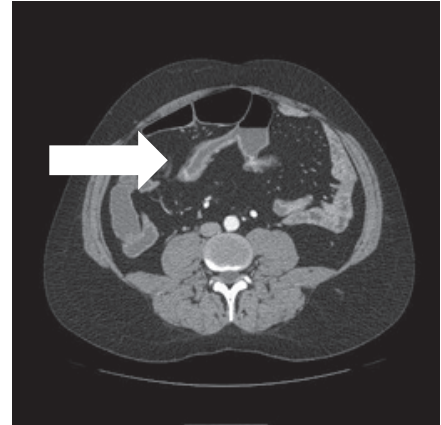

Early Crohn's disease:

Inflammation (clinical, biological, endoscopic, radiologic evidence of disease activity)

No fistula, abscess or stricture

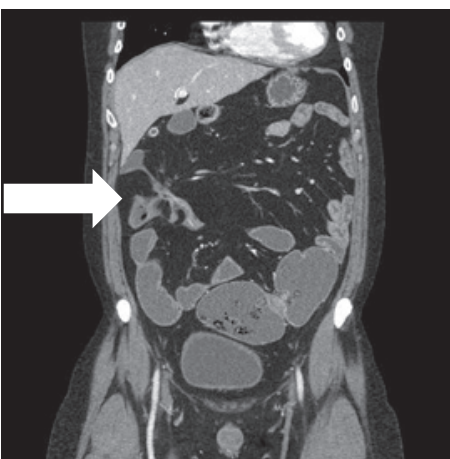

-ate Crohn's disease:

Bowel damage (fistula, abscess, stricture)

Impairment of GI functioning

Colorectal cancer (formerly, the American Rheumatism Association) 1987 revised criteria ${ }^{47}$ as a disease duration of $\leq 2$ years, age $\geq 18$ years, and active disease with $\geq 6$ of 66 swollen joints, $\geq 6$ of 68 tender joints, and either an erythrocyte sedimentation rate $\geq 28 \mathrm{~mm} / \mathrm{h}$ or a global health score of $\geq 20 \mathrm{~mm}$ on a $0-100 \mathrm{~mm}$ visual analogue scale, where 0 is the best and 100 is the worst (table 1). This definition has been widely used in recent disease modification trials in rheumatoid arthritis such as the BeSt study, ${ }^{36}$ even though significant variations in the definition of disease duration exist. The time frame of early rheumatoid arthritis ranged up to 5 years in some studies. ${ }^{49}{ }^{50}$ At this time, 'early rheumatoid arthritis' is defined as $\leq 6-24$ months of symptoms. ${ }^{50}$ The median duration of symptoms at the time of enrolment in most early rheumatoid arthritis cohorts was $5-8$ months. ${ }^{50-53}$ Very early rheumatoid arthritis has been defined with a maximum duration of symptoms of 12 weeks. ${ }^{50} 54$ Currently, the American College of Rheumatology and the European League Against Rheumatism are in the process of defining new criteria for rheumatoid arthritis that will allow earlier diagnosis and treatment of patients in both clinical practice and clinical trials. ${ }^{55}$

\section{Defining early Crohn disease}

In the study by D'Haens et al, ${ }^{46}$ early Crohn disease was defined by the investigators as 'a diagnosis within 4 years in patients who had not previously received corticosteroids, antimetabolites or biological agents'. This empirical definition did not take into account bowel damage or impaired gastrointestinal functioning. A definition that is more analogous to the American College of Rheumatology defi- nition of early rheumatoid arthritis may better define an early disease population.

Only patients with evidence of clinical and biological disease activity will be considered as having early active Crohn disease. The Crohn Disease Activity Index (CDAI) is a validated instrument which is used to measure disease activity in clinical trials. ${ }^{56}$ The cut-off value of 220 points is generally chosen to distinguish moderate to severely active Crohn disease. ${ }^{56}$ In a Scandinavian population-based study, the mean and median C-reactive protein (CRP) concentration at diagnosis were 51 and $33 \mathrm{mg} / \mathrm{l}$ (range 0-266 mg/l). ${ }^{57}$ A total of $25 \%$ of patients $(44 / 176)$ had a CRP level below $10 \mathrm{mg} / \mathrm{l}$ at diagnosis. In order to limit the risk of including patients with symptoms related to functional disorders, a cut-off value of $10 \mathrm{mg} / 1$ seems reasonable. Because some patients may have 
Table 1 Proposal for a definition of early Crohn disease and comparison with the definition of early rheumatoid arthritis by the American College of Rheumatology 47

\begin{tabular}{lll}
\hline Early rheumatoid arthritis & Criterion & Early Crohn disease \\
\hline$\geq 6$ of 66 swollen joints, & Active disease & Crohn disease Activity Index (CDAl) $>220$
\end{tabular}

Erythrocyte sedimentation rate $\geq 28 \mathrm{~mm} / \mathrm{h} \quad$ Active disease

or a global health score of $\geq 20 \mathrm{~mm}$
Age

Immunomodulators (azathioprine

6-mercaptopurine, methotrexate), biologics, corticosteroids (previously steroid-dependent with oral steroids or any treatment with intravenous steroids)* Bowel damage

Surgery

Endoscopy procedures

Impaired Gl functioning
C-reactive protein $>10 \mathrm{mg} / \mathrm{l}$ or significant endoscopic (large coalescent and deep ulcerations covering more than $10 \%$ of the mucosal area of at least one segment of the colorectum) or radiological evidence (CT or MRI bowel enhancement) of disease activity or positive faecal markers No limit of age (both paediatric and adult patients can be included)

No previous or current use

No fistula (including perianal fistulas), abscess, stricture (wall thickening and luminal narrowing with prestenotic dilatation-defined as a diameter greater than the normal diameter of the small bowel or colon) on CT or MRI† No history of Crohn disease-related surgery (minor or major surgical procedures)

No history of endoscopic balloon dilation of a stricture Normal faecal continence, no previous or current use of oral or parenteral substitution (vitamins, minerals), no enteral or parenteral nutrition since diagnosis

\begin{tabular}{l}
$\leq 2$ years Disease duration \\
\hline The patient must fulfil all inclusion criteria without any exception. \\
As a prerequisite, the previous diagnosis of Crohn disease has to be confirmed according to the criteria adopted by Lennard-Jones. ${ }^{48}$ \\
${ }^{*}$ All 5 -aminosalicylate formulations permitted (previous or current use).
\end{tabular}

${ }^{*}$ All 5 -aminosalicylate formulations permitted (previous or current use).

tWhen available, MRI is preferred.

active Crohn disease with normal CRP concentrations despite abnormal smallbowel radiographic imaging, ${ }^{58}{ }^{59}$ significant endoscopic or radiological evidence (CT or MRI bowel enhancement ${ }^{60}{ }^{61}$ ) of disease activity can be included in the definition as an alternative to the CRP concentration cut-off value. Patients with large coalescent and deep ulcerations covering more than $10 \%$ of the mucosal area of at least one segment of the colorectum will be considered as having endoscopic evidence of active inflammation. ${ }^{62}$ When available, active disease may be detected by using faecal markers, such as faecal calprotectin or lactoferrin. ${ }^{59}$

We propose that both paediatric and adult patients with Crohn disease can be included in the definition of early Crohn disease. First, about 10\% of Crohn disease is diagnosed in childhood. ${ }^{8} 63$ Second, Crohn disease results in paediatric-specific complications, such as growth failure and delayed puberty. ${ }^{64} 65$ Third, in a population-based study from France, disease complications were already present in $29 \%$ of children at diagnosis, and disease progression led to a cumulative incidence of disease complication of $59 \%$ during a median follow-up of 7 years ${ }^{8}$ with a cumulative incidence of surgery of $34 \%$ at 5 years from diagnosis. 8 Overall, the consequences of Crohn disease can severely impair physical and social functioning (disability $^{66}$ ) in paediatric patients. ${ }^{67}$
Patients with early Crohn disease should be naive to drugs that are potentially disease-modifying. These drugs include azathioprine, 6-mercaptopurine, methotrexate and biological agents, such as TNF- $\alpha$ antagonists and natalizumab. Corticosteroids are not effective for maintaining remission. ${ }^{68}$ Therefore, the use of oral corticosteroids without steroiddependent disease is not an exclusion criterion from the definition of early Crohn disease. However, patients should not have previously been steroid-dependent (defined as being unable to reduce corticosteroids below the equivalent of prednisolone $10 \mathrm{mg} /$ day or budesonide below $6 \mathrm{mg}$ /day within 3 months of starting corticosteroids, without recurrent active disease, or who have a relapse within 3 months of stopping corticosteroids ${ }^{69}$ ) or have received intravenous steroids. Because mesalamine and antibiotics have no or little efficacy in treating Crohn disease and are not disease-modifying agents, their use will be permitted. ${ }^{2}$

Crohn disease is known to be a transmural disease with progression from inflammatory disease to complications of stricture, fistula and abscess. Hence, the evaluation of the whole intestinal wall is required in Crohn disease, and a combination of both colonoscopic examination of the mucosa of the terminal ileum and colon, and radiographic or magneticresonance examination of the small bowel will be necessary to demonstrate the presence of inflammation and the absence of complications in patients with early Crohn disease. While high-quality CT is available in almost all centres managing patients with Crohn disease, there is still a limited access to MRI. MRI is preferred when both techniques are available because of the risks of exposure to ionising radiation from serial CT examinations in patients with Crohn disease, especially those under the age of 35 years. ${ }^{7071}$ Several studies now indicate that MRI is accurate for detecting disease activity and assessing disease severity in Crohn disease. ${ }^{61} 72$ In other cases, CT will be performed. In a Norwegian population-based study, at the time of diagnosis, 121 (61\%) had non-stricturing non-penetrating disease, 55 (28\%) had stricturing complications, and 24 (12\%) had penetrating complications. ${ }^{73}$ In Olmsted County, Minnesota, USA, 19\% of Crohn disease patients had already experienced penetrating or stricturing complications within the first 90 days of diagnosis, and fully half of all patients had experienced an intestinal complication 20 years after diagnosis. ${ }^{7}$ To be considered as early Crohn disease, patients should undergo gastrointestinal imaging, and no fistulas (including perianal fistulas), abscesses or strictures (defined as wall thickening and luminal narrowing with prestenotic dilatation-defined as a diameter greater than the normal 
diameter of the small bowel or colon) should be found. In addition, there should be no history of Crohn disease-related surgery, including minor or major surgical procedures (intestinal resection, stricturoplasty, diverting procedure, fistulectomy, fistulotomy, drainage of abscess, placement of seton(s)), and no history of any endoscopic balloon dilation of a Crohn disease stricture. For studies that have the primary aim of preventing bowel damage, as opposed to preventing both bowel damage AND maintaining normal gastrointestinal physiology (see below), it might be reasonable to consider including patients who have had a previous surgical resection and have recurrent inflammatory disease without strictures, fistulas or abscesses. However, such patients should not be designated as having early Crohn disease.

As discussed above, future therapeutic goals for Crohn disease may include not only a reduction in bowel damage but also maintaining normal gastrointestinal physiology. ${ }^{2}$ Thus, in addition to absence of structural damage and surgical loss of bowel, patients with early Crohn disease should have a normal gastrointestinal function, which consists of normal faecal continence (history of only one episode of incontinence is sufficient to exclude the patient from the definition of early Crohn disease), no requirement for oral or parenteral vitamin or mineral supplementation (ie, vitamin $B_{12}$, folate, fat-soluble vitamins, etc), and no requirement for nutritional support (enteral nutrition supplementation or parenteral nutrition) since diagnosis. Iron supplementation for iron-deficiency anaemia due to gastrointestinal blood loss is acceptable for inclusion as early Crohn disease.

As suggested by subgroup analyses of large randomised placebo-controlled trials, TNF- $\alpha$ antagonists may be more effective in patients with disease duration less than 1 or 2 years. ${ }^{43} 44$ Ideally, 1 year should be part of the definition of early Crohn disease, when the economic burden of the disease and efficacy of TNF antagonists are maximal. ${ }^{43}$ ${ }^{74}$ Similarly to rheumatoid arthritis, ${ }^{47}$ a disease duration $<2$ years is more realistic and will allow the identification of a sufficient number of patients with early Crohn disease, particularly in clinical trials, without including those with longstanding disease. However, in the future, consideration should be given to developing a definition of very early Crohn disease (possibly $\leq 12$ weeks, which is the definition used for very early rheumatoid arthritis).

Our proposal for a definition of early Crohn disease is shown in table 1.

\section{DISCUSSION}

Both immunopathological and clinical evidence indicates that early intervention may be a prerequisite for demonstrating the efficacy of drugs that are potentially disease-modifying in patients with Crohn disease. A Europe-wide population-based cohort showed that total and hospitalisation costs were much higher in the first year after diagnosis than in subsequent years. ${ }^{74}$ A Markov chain analysis of this Europe-wide population-based cohort revealed that surgery accounted for $63 \%$ of total healthcare costs in first year, rising to $90 \%$ after 6 years of follow-up ${ }^{75}$ Clinical trials that identify therapies that change this clinical course are needed. Defining early Crohn disease is a prerequisite to undertaking such trials.

Functional and structural damage are increasingly being taken into account in assessing the impact of chronic diseases on the individual, as well as the effectiveness of treatments to impact on the natural course of the disease, including multiple sclerosis $^{76} 77$ and rheumatoid arthritis. ${ }^{36}$ We have proposed here a definition taking account both concepts. This article is not a consensus document and should be regarded as a position paper. The next step will involve defining early Crohn disease during a consensus conference involving national and international experts in the field. After the testing and validation phases, this definition may be used in clinical trials and to evaluate drugs for disease modification of Crohn disease. Clinical trials using this definition of early Crohn disease will also help in defining

\section{Box 1 Rationale for defining early \\ Crohn disease}

- Crohn disease is a chronic progressive destructive disease.

- Approximately one-fifth of adult and paediatric patients already have evidence of a stricturing or penetrating intestinal complications at diagnosis.

- Effective intervention before the onset of bowel damage (stricture, fistula, abscess) is required to modify the clinical course of Crohn disease.

- Current molecular tools, such as genetic and serological markers, do not allow the identification of subclinical intestinal inflammation with accuracy.

- At present, the only way to define early Crohn disease is to use clinical, biological, endoscopic and radiological criteria.
Box 2 Rationale for early intervention

in Crohn disease

- Immunopathological evidence supports the concept of early intervention in Crohn disease.

- Subgroup analyses of large randomised placebo-controlled trials suggested that tumour necrosis factor antagonists (adalimumab, certolizumab pegol) may be more effective in patients with disease duration less than 1 or 2 years.

- Many adverse effects may occur at a lower frequency among patients with early rheumatoid arthritis treated with tumour necrosis factor antagonists.

- A formal definition of early Crohn disease is needed to develop new therapeutic strategies aimed at modifying the clinical course of the disease.

patients who might benefit from early treatment initiation, thus limiting the risk of overtreatment of patients with minimal or inactive disease on one hand and patients who already have irreversible complications on the other. Finally, such clinical studies will evaluate whether specific therapeutic regiments are costeffective in the treatment of Crohn disease by improving quality of life, reducing hospitalisation, surgeries and other

Box 3 Main points of the proposed definition of early Crohn disease (patient must fulfil all criteria without any exception)

- Adult or paediatric patient with an established diagnosis of Crohn disease.

- Clinical and biological, endoscopic or radiological evidence of disease activity or positive faecal markers.

- No impairment of gastrointestinal function (normal faecal continence, no oral or parenteral vitamin or mineral supplementation and no nutritional support since diagnosis).

- No bowel damage (stricture, fistula, abscess) on computed tomography or MRI.

- Disease duration less than 2 years.

- Being naïve to potential disease-modifying agents.

- Not having undergone Crohn diseaserelated surgery or therapeutic endoscopic procedures. 
interventions, ${ }^{78}$ and preventing both bowel damage (stricture, fistula, abscess) and impaired gastrointestinal physiology.

\section{Competing interests None.}

Received 20 September 2009

Accepted 22 September 2009

Gut 2010;59:141-147. doi:10.1136/gut.2009.187120

\section{REFERENCES}

1. Mader R, Keystone E. Optimizing treatment with biologics. J Rheumatol Supp/ 2007;80:16-24.

2. Sandborn WJ. Current directions in IBD therapy: what goals are feasible with biological modifiers? Gastroenterology 2008;135:1442-7.

3. D'Haens GR, Fedorak R, Lemann M, et al. Endpoints for clinical trials evaluating disease modification and structural damage in adults with Crohn's disease. Inflamm Bowel Dis 2009:15:1599-604.

4. Peyrin-Biroulet L, Bigard MA, Malesci A, et al. Stepup and top-down approaches to the treatment of Crohn's disease: early may already be too late. Gastroenterology 2008;135:1420-2.

5. Cosnes J, Cattan S, Blain A, et al. Long-term evolution of disease behavior of Crohn's disease. Inflamm Bowel Dis 2002;8:244-50.

6. Louis $\mathbf{E}$, Collard A, Oger AF, et al. Behaviour of Crohn's disease according to the Vienna classification: changing pattern over the course of the disease. Gut 2001; 49:777-82.

7. Thia KT, Sandborn WJ, Harmsen WS, et al. The evolution of Crohn's disease in a population-based cohort from Olmsted County, Minnesota, 1970-2004. Gastroenterology. In press.

8. Vernier-Massouille G, Balde M, Salleron J, et al Natural history of pediatric Crohn's disease: a population-based cohort study. Gastroenterology 2008; 135:1106-13.

9. Dhillon SLEJ, Tremaine WJ, Jewell DA, et al. The natural history of surgery for Crohn's disease in a population-based cohort from Olmsted County, Minnesota [Abstract 825]. Am J Gastroenterol 2005; 100(9 Suppl):305S.

10. Young A, Huizinga T. Early rheumatoid arthritis. Best Pract Res Clin Rheumatol 2009;23:1-2.

11. Klareskog L, Catrina Al, Paget S. Rheumatoid arthritis. Lancet 2009;373:659-72.

12. Barrett JC, Hansoul S, Nicolae DL, et al. Genomewide association defines more than 30 distinct susceptibility loci for Crohn's disease. Nat Genet 2008;40:955-62

13. Peyrin-Biroulet L, Standaert-Vitse A, Branche J, et al. IBD serological panels: facts and perspectives. Inflamm Bowel Dis 2007;13:1561-6.

14. Peyrin-Biroulet L, Desreumaux P, Sandborn WJ, et al. Crohn's disease: beyond antagonists of tumour necrosis factor. Lancet 2008;372:67-81.

15. Israeli E, Grotto I, Gilburd B, et al. AntiSaccharomyces cerevisiae and antineutrophil cytoplasmic antibodies as predictors of inflammatory bowel disease. Gut 2005;54:1232-6.

16. Dubinsky MC, Kugathasan S, Mei L, et al. Increased immune reactivity predicts aggressive complicating Crohn's disease in children. Clin Gastroenterol Hepatol 2008;6:1105-11.

17. El-Gabalawy H. The preclinical stages of RA: lessons from human studies and animal models. Best Pract Res Clin Rheumatol 2009:23:49-58.

18. Raza K, Falciani F, Curnow SJ, et al. Early rheumatoid arthritis is characterized by a distinct and transient synovial fluid cytokine profile of T cell and stromal cell origin. Arthritis Res Ther 2005; 7:784-95R.

19. Gerli R, Bistoni O, Russano A, et al. In vivo activated $\mathrm{T}$ cells in rheumatoid synovitis. Analysis of Th1- and Th2-type cytokine production at clonal level in different stages of disease. Clin Exp Immunol 2002;129:549-55.

20. Bucht A, Larsson P, Weisbrot L, et al. Expression of interferon-gamma (IFN-gamma), IL-10, IL-12 and transforming growth factor-beta (TGF-beta) mRNA in synovial fluid cells from patients in the early and late phases of rheumatoid arthritis (RA). Clin Exp Immunol 1996;103:357-67

21. Morita Y, Yamamura M, Kawashima M, et al. Flow cytometric single-cell analysis of cytokine production by CD4 + T cells in synovial tissue and peripheral blood from patients with rheumatoid arthritis. Arthritis Rheum 1998;41:1669-76.

22. Strober W, Fuss IJ, Blumberg RS. The immunology of mucosal models of inflammation. Annu Rev Immunol 2002;20:495-549

23. Desreumaux $\mathbf{P}$, Brandt E, Gambiez L, et al. Distinct cytokine patterns in early and chronic ileal lesions of Crohn's disease. Gastroenterology 1997;113:118-26.

24. Kugathasan S, Saubermann LJ, Smith L, et al. Mucosal T-cell immunoregulation varies in early and late inflammatory bowel disease. Gut 2007:56:1696-705.

25. Spencer DM, Veldman GM, Banerjee S, et al. Distinct inflammatory mechanisms mediate early versus late colitis in mice. Gastroenterology 2002:122:94-105.

26. Bamias G, Martin C, Mishina M, et al. Proinflammatory effects of $\mathrm{TH} 2$ cytokines in a murine model of chronic small intestinal inflammation. Gastroenterology 2005;128:654-66.

27. Cominelli F. Early and late gut immune responses in IBD. J Pediatr Gastroenterol Nutr 2008:46| Suppl):20E.

28. Rivera-Nieves J, Ho J, Bamias G, et al. Antibody blockade of CCL25/CCR9 ameliorates early but not late chronic murine ileitis. Gastroenterology 2006;131:1518-29.

29. Dwosh IL, Stein HB, Urowitz MB, et al. Azathioprine in early rheumatoid arthritis. comparison with gold and chloroquine. Arthritis Rheum 1977;20:685-92.

30. Scott DL. What have we learnt about the development and progression of early RA from RCTs? Best Pract Res Clin Rheumatol 2009;23:13-24.

31. Genovese MC, Bathon JM, Martin RW, et al. Etanercept versus methotrexate in patients with early rheumatoid arthritis: two-year radiographic and clinical outcomes. Arthritis Rheum 2002;46:1443-50

32. Smolen JS, Van Der Heijde DM, St Clair EW, et al. Predictors of joint damage in patients with early rheumatoid arthritis treated with high-dose methotrexate with or without concomitant infliximab: results from the ASPIRE trial. Arthritis Rheum 2006;54:702-10.

33. Breedveld FC, Weisman $\mathrm{MH}$, Kavanaugh AF, et al. The PREMIER study: A multicenter, randomized double-blind clinical trial of combination therapy with adalimumab plus methotrexate versus methotrexate alone or adalimumab alone in patients with early, aggressive rheumatoid arthritis who had not had previous methotrexate treatment. Arthritis Rheum 2006;54:26-37

34. Durez P, Malghem J, Nzeusseu Toukap A, et al. Treatment of early rheumatoid arthritis: a randomized magnetic resonance imaging study comparing the effects of methotrexate alone, methotrexate in combination with infliximab, and methotrexate in combination with intravenous pulse methylprednisolone. Arthritis Rheum 2007;56:3919-27.

35. Castro-Rueda H, Kavanaugh A. Biologic therapy for early rheumatoid arthritis: the latest evidence. Curr Opin Rheumatol 2008;20:314-9.

36. Goekoop-Ruiterman YP, de Vries-Bouwstra JK, Allaart CF, et al. Clinical and radiographic outcomes of four different treatment strategies in patients with early rheumatoid arthritis (the BeSt study) randomized, controlled trial. Arthritis Rheum 2005;52:3381-90.

37. Van Der Kooij SM, Goekoop-Ruiterman YP, De VriesBouwstra JK, et al. Drug-free remission, functioning and radiographic damage after 4 years of responsedriven treatment in patients with recent onset rheumatoid arthritis. Ann Rheum Dis 2009;68:914-21

38. Kavanaugh A, Keystone EC. The safety of biologic agents in early rheumatoid arthritis. Clin Exp Rheumatol 2003;21:S203-8.

39. Krause U. Early or late operation in the treatment of Crohn's disease. Scand J Gastroenterol 1971;6:479-81.

40. Aratari A, Papi C, Leandro G, et al. Early versus late surgery for ileo-caecal Crohn's disease. Aliment Pharmacol Ther 2007;26:1303-12.

41. Markowitz J, Grancher K, Kohn N, et al. A multicenter trial of 6-mercaptopurine and prednisone in children with newly diagnosed Crohn's disease. Gastroenterology 2000;119:895-902.

42. Cosnes J, Nion-Larmurier I, Beaugerie L, et al. Impact of the increasing use of immunosuppressants in Crohn's disease on the need for intestinal surgery. Gut 2005; 54:237-41.

43. Sandborn WJ, Colombel JF, Panes J, et al. Higher remission and maintenance of response rates wih subcutaneously monthly certolizumab in patients recent-onset Crohn's disease:data from PRECISE 2 [abstract 1109]. Am J Gastroenterol 2006;101:454-5S.

44. Schreiber S, Reinisch W, Colombel JF, et al. Early Crohn's disease shows high levels of remission to therapy with adalimumab:sub-analysis of CHARM Gastroenterology 2007:132:147A.

45. Lionetti P, Bronzini F, Salvestrini C, et al. Response to infliximab is related to disease duration in paediatric Crohn's disease. Aliment Pharmacol Ther 2003; 18:425-31

46. D'Haens G, Baert F, van Assche G, et al. Early combined immunosuppression or conventional management in patients with newly diagnosed Crohn's disease: an open randomised trial. Lancet 2008; 371:660-7.

47. Arnett FC, Edworthy SM, Bloch DA, et al. The American Rheumatism Association 1987 revised criteria for the classification of rheumatoid arthritis. Arthritis Rheum 1988;31:315-24.

48. Lennard-Jones JE. Classification of inflammatory bowel disease. Scand J Gastroenterol 1989;(170 Suppl):2-6.

49. Helliwell PS. The semeiology of arthritis: discriminating between patients on the basis of their symptoms. Ann Rheum Dis 1995;54:924-6.

50. Sokka T, Makinen H. Drug management of early rheumatoid arthritis-2008. Best Pract Res Clin Rheumatol 2009;23:93-102.

51. Kaarela K. Prognostic factors and diagnostic criteria in early rheumatoid arthritis. Scand J Rheumatol Suppl 1985; 57:1-54

52. Mottonen TT. Prediction of erosiveness and rate of development of new erosions in early rheumatoid arthritis. Ann Rheum Dis 1988; 47:648-53

53. Hannonen $\mathbf{P}$, Mottonen $\mathrm{T}$, Hakola $\mathrm{M}$, et al. Sulfasalazine in early rheumatoid arthritis. A 48-week double-blind, prospective, placebo-controlled study. Arthritis Rheum 1993;36:1501-9.

54. Machold KP, Stamm TA, Eberl GJ, et al. Very recent onset arthritis-clinical, laboratory, and radiological findings during the first year of disease. J Rheumatol 2002;29:2278-87.

55. Aletaha D, Huizinga TW. The use of data from early arthritis clinics for clinical research. Best Pract Res Clin Rheumatol 2009;23:117-23.

56. Best WR, Becktel JM, Singleton JW, et al. Development of a Crohn's disease activity index. 
National Cooperative Crohn's Disease Study. Gastroenterology 1976;70:439-44.

57. Henriksen M, Jahnsen J, Lygren I, et al. C-reactive protein: a predictive factor and marker of inflammation in inflammatory bowel disease. Results from a prospective population-based study. Gut 2008:57:1518-23.

58. Solem CA, Loftus EV Jr, Tremaine WJ, et al Correlation of $\mathrm{C}$-reactive protein with clinical, endoscopic, histologic, and radiographic activity in inflammatory bowel disease. Inflamm Bowel Dis 2005; 11:707-12

59. Jones J, Loftus EV Jr, Panaccione $\mathrm{R}$, et al. Relationships between disease activity and serum and fecal biomarkers in patients with Crohn's disease. Clin Gastroenterol Hepatol 2008;6:1218-24.

60. Colombel JF, Solem CA, Sandborn WJ, et al. Quantitative measurement and visual assessment of ileal Crohn's disease activity by computed tomography enterography: correlation with endoscopic severity and $C$ reactive protein. Gut 2006:55:1561-7.

61. Siddiki HA, Fidler JL, Fletcher JG, et al. Prospective comparison of state-of-the-art MR enterography and CT enterography in small-bowel Crohn's disease. AJR Am J Roentgenol 2009;193:113-21.

62. Allez M, Lemann M, Bonnet J, et al. Long term outcome of patients with active Crohn's disease exhibiting extensive and deep ulcerations a colonoscopy. Am J Gastroenterol 2002;97:947-53.
63. Loftus CG, Loftus EV Jr, Harmsen WS, et al Update on the incidence and prevalence of Crohn's disease and ulcerative colitis in Olmsted County, Minnesota, 1940-2000. Inflamm Bowel Dis 2007:13:254-61.

64. Saab R, Furman WL. Epidemiology and management options for colorectal cancer in children. Paediatr Drugs 2008;10:177-92

65. Wiskin AE, Wootton SA, Beattie RM. Nutrition issues in pediatric Crohn's disease. Nutr Clin Pract 2007;22:214-22.

66. Peyrin-Biroulet L, Cieza A, Sandborn WJ, et al. Disability in inflammatory bowel diseases: Developing ICF core sets for patients with inflammatory bowel diseases based on the international classification of functioning, disability, and health. Inflamm Bowel Dis. In press.

67. Hyams JS, Markowitz JF. Can we alter the natural history of Crohn disease in children? J Pediat Gastroenterol Nutr 2005;40:262-72.

68. Steinhart $\mathbf{A H}$, Ewe K, Griffiths AM, et al. Corticosteroids for maintenance of remission in Crohn's disease. Cochrane Database Syst Rev 2003: CD000301.

69. Stange EF, Travis SP, Vermeire S, et al. European evidence based consensus on the diagnosis and management of Crohn's disease: definitions and diagnosis. Gut 2006;55(1 Suppl):i1-15.

70. Peloquin JM, Pardi DS, Sandborn WJ, et al. Diagnostic ionizing radiation exposure in a population- based cohort of patients with inflammatory bowe disease. Am J Gastroenterol 2008;103:2015-22.

71. Brenner DJ, Hall EJ. Computed tomography—an increasing source of radiation exposure. N Engl J Med 2007;357:2277-84

72. Rimola J, Rodriguez S, Garcia Bosch 0, et al. Magnetic resonance for assessment of disease activity and severity in Crohn disease. Gut 2009:58:1113-20.

73. Henriksen M, Jahnsen J, Lygren I, et al. Clinica course in Crohn's disease: results of a five-year population-based follow-up study (the IBSEN study). Scand J Gastroenterol 2007;42:602-10.

74. Odes S, Vardi H, Friger M, et al. Cost analysis and cost determinants in a European inflammatory bowe disease inception cohort with 10 years of follow-up evaluation. Gastroenterology 2006;131:719-28.

75. Odes S, Vardi $\mathrm{H}$, Friger $\mathrm{M}$, et al. Clinical course and cost of healthcare in Crohn's disease: Markov chain analysis of a European prospectively recruited population-based cohort. JCC 2009:3:S35.

76. Compston A, Coles A. Multiple sclerosis. Lancet 2008;372:1502-17.

77. Ebers GC, Heigenhauser L, Daumer M, et al. Disability as an outcome in MS clinical trials. Neurology 2008:71:624-31.

78. Lichtenstein GR, Hanauer SB, Sandborn WJ. Management of Crohn's disease in adults. Am J Gastroenterol 2009:104:465-83.

\section{Editor's quiz: GI snapshot}

\section{A 61-year-old man with abdominal pain for 6 months}

\section{CLINICAL PRESENTATION}

This 61-year-old man presented complaining of a 6-month history of intermittent abdominal fullness and dull periumbilical pain. There were no obvious aggravating factors, no radiation and no vomiting. He noticed loose stool with increased frequency of defecation about three to four times per day unrelated to eating. There was no history of previous abdominal surgery. Physical examination revealed a soft abdomen with mild distension. The initial laboratory data, including amylase, lipase and haemogram, were within normal limits. Plain abdominal radiography revealed focal dilated bowel gas over left upper quadrant. Abdominal computed tomography (CT) (figure 1) was performed. Then he was referred to our hospital for further evaluation.

\section{QUESTION}

What is your diagnosis?

See page 185 for the answer.

\section{Cheng-Hao Tseng, ${ }^{1,4}$ Jyh-Ming Liou, ${ }^{1}$ Kao-Lang Liu, ${ }^{2}$ Hsiu-Po Wang ${ }^{1,3}$}

'Department of Internal Medicine, National Taiwan University Hospital, Taipei, Taiwan Department of Medical Imaging, National Taiwan University Hospital, Taipei, Taiwan Departments of Internal Medicine, National Taiwan University Hospital Yun-Lin Branch, Yun-Lin,Taiwan; 'Department of Internal Medicine, E-DA Hospital, Kaoshiung, Taiwan

Correspondence to Dr Hsiu-Po Wang, Department of Internal Medicine, National Taiwan University Hospital and National Taiwan University College of Medicine, No. 7 . Chung-Shan South Road, Taipei, Taiwan; wanghp@ntu.edu.tw

Competing interests None.

Patient consent Obtained.

Provenance and peer review Not commissioned; externally peer reviewed. Gut 2010;59:147. doi:10.1136/gut.2009.178616

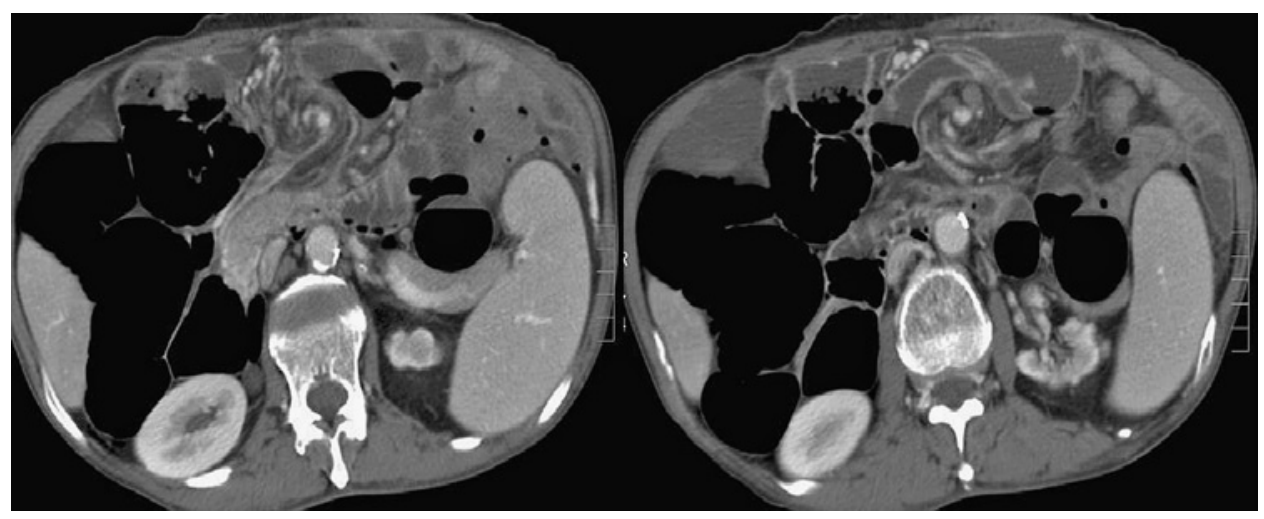

Figure 1 Two cross-sectional computed tomography (CT) images. 